\title{
11
}

\section{Regional Climate Change over South Asia}

\author{
John Caesar and Tamara Janes
}

\subsection{Introduction}

The combination of a highly variable climate, a large and increasing population and a high reliance on water dependent sectors such as agriculture means that South Asia could be particularly at risk to future climate change and variability. Changes in the climate occur in a variety of ways, including changes in mean temperature, changes in extreme daily maximum temperatures and changes in the length, frequency or magnitude of heatwaves. Similarly, increases or decreases in the frequency and magnitude of precipitation could affect water availability or change the characteristics of floods or droughts. For a monsoon climate, such as South Asia, changes in seasonality could also have a large impact on the quantities and timings of water availability, a critical factor in agrarian societies. Climate change and variability is therefore a key underpinning input into many of the biophysical models which form part of this research. The focus in this chapter is on climate projections

\section{J. Caesar $(\bowtie) \bullet T$. Janes}

Met Office Hadley Centre for Climate Science and Services,

Exeter, Devon, UK 


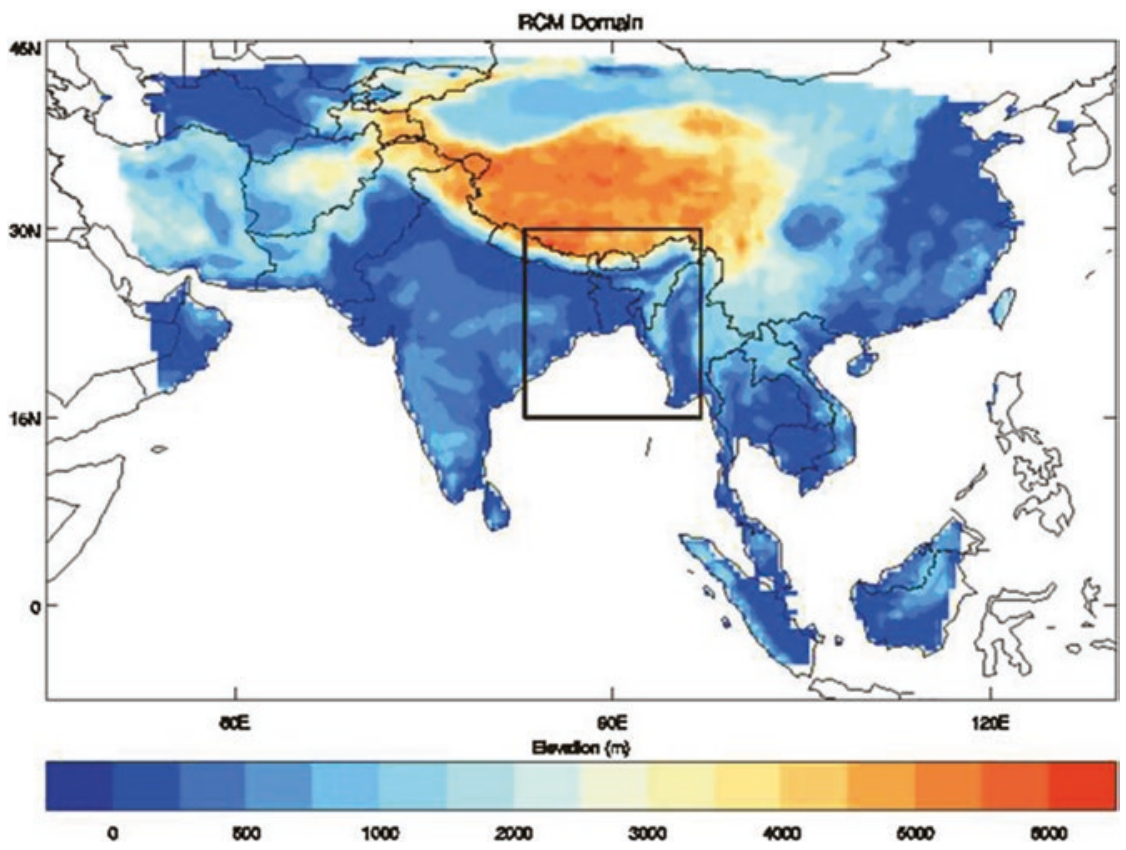

Fig. 11.1 Regional model domain for South Asia used in this research showing land surface elevation. The solid box $\left(83-97^{\circ} \mathrm{E}, 15-30^{\circ} \mathrm{N}\right)$ shows the analysis region used throughout this chapter. Area averaged values used throughout this chapter are based upon all land grid points within this box (Caesar et al. 2015-Reproduced by permission of The Royal Society of Chemistry)

over the land regions of Bangladesh and the wider Ganges-BrahmaputraMeghna (GBM) basins (Fig. 11.1). Climate change over the marine regions of the Bay of Bengal is considered in more detail in Chap. 14.

This chapter provides an overview of the climate change projections used and a consideration of the uncertainty in those projections. The basis for the projections is a widely used medium-high scenario (SRES A1B; Nakićenović et al. 2000) of global increases in greenhouse gas emissions. An important component of this research is the use and integration of a range of biophysical models where climate model data (both for the current period and future projections) is a key input. Whilst this chapter focuses upon temperature and rainfall projections, a wide range of other climate variables (atmospheric, land surface and ocean) were provided from the model simulations to input into other biophysical models. 


\subsection{Climate of Bangladesh}

Bangladesh is widely recognised as being vulnerable to extreme weather events and climate change. A large proportion of the country's topography is low-lying and forms the delta of the GBM rivers (Karim and Mimura 2008). The country is densely populated and socio-economically challenged with agriculture playing a significant role in livelihoods. Bangladesh has a tropical monsoon climate, and this brings high temperature, heavy rainfall, high humidity and strong seasonal variations. Changes in precipitation can lead to enhanced flooding or drought as well as dislocation between the timing of rainfall and the agricultural calendar. Seasons can be separated into four groups, differentiated by the percentage of the mean annual rainfall falling in each season (Islam and Uyeda 2005):

- Pre-monsoon (March-May) - 20 per cent

- Monsoon (June-September) -62.5 per cent

- Post-monsoon (October-November) -15.5 per cent

- Winter (December-February) -2 per cent

These estimates vary between studies, and post-monsoon rainfall in particular can be affected by the impacts of cyclones, but the bulk of annual rainfall occurs during the summer monsoon, with some studies reporting higher proportions of up to $70-80$ per cent of the annual total (Shahid 2010a). Winter generally sees much cooler and drier conditions and accounts for only two to four per cent of annual rainfall totals. Tropical cyclones are a particular weather-related hazard for Bangladesh, and can bring periods of intense rainfall, particularly during the postmonsoon season.

Studies that have examined observed climate changes over Bangladesh show that during the twentieth century annual mean temperatures increased by around $0.5^{\circ} \mathrm{C}$ (Immerzeel 2008) and were accompanied by increasing rainfall (Shahid 2010b).

Sea-level rise and storm surges associated with tropical cyclones are key risks for this region. These factors are addressed further in Chaps. 14 and 16 , including future projections of extreme storm surges. This assessment 
uses output from the regional climate simulations (which are atmosphereonly models) presented in this chapter, alongside sea-level rise projections from the associated global models, which simulate both the atmosphere and oceans, albeit at a coarser spatial resolution.

\subsection{Climate Model Simulations}

Simulations of the global climate system are made using computer models, known as general circulation models (GCMs), and these are often used to simulate the impact of different greenhouse gas concentrations in the atmosphere in the future. GCMs typically have coarse spatial resolutions and simulate the global atmosphere split into large 'boxes' of several hundred kilometres in size. They are not necessarily able to provide the high-resolution climate change information that is now often required by climate impacts and adaptation studies. To enable a highresolution representation of climate change at regional and local levels, regional climate models (RCMs) can be used to provide higher-resolution grids (typically $50 \mathrm{~km}$ or finer) and provide better representations of features such as coastlines and mountains and their effects on the climate (Giorgi et al. 2009). RCMs take output of the global scale GCM and use it to drive a simulation over a specific region at a much higher spatial resolution. In this work, the Met Office Hadley Centre HadRM3P model with a $25 \mathrm{~km} \times 25 \mathrm{~km}$ spatial grid resolution has been used, downscaling the output of the HadCM3 GCM (Caesar et al. 2015). The focus in the past has tended to be on climate modelling over the wider South Asia region, and there had been few studies using highresolution climate models over the Bangladesh region, though this number is beginning to increase (e.g. Caesar et al. 2015; Kumar et al. 2013; Mathison et al. 2013).

Previous climate model studies have projected increases in temperature over Bangladesh by the end of the twenty-first century (e.g. May 2004; Agrawala et al. 2003). Projections also indicate an increase in annual rainfall totals in the future (Immerzeel 2008; Islam et al. 2008) and an increase in the intensity of rainfall events (May 2004; Agrawala et al. 2003). The uncertainty associated with these model projections is 
large, partly as a result of uncertainty in the possible range of future greenhouse gas emissions, and also in part due to differences between the characteristics of different climate models (Immerzeel 2008; Islam et al. 2008; IPCC 2013). The climate projections used for this research make use of an approach called a 'perturbed physics ensemble' (Collins et al. 2006). This involves running the GCM multiple times but each time making small changes to the representation of certain physical processes which may be uncertain and difficult to constrain using observations (Murphy et al. 2004). One example of such a variable is critical relative humidity, which relates the humidity of the atmosphere in the model grid box with the amount of cloud simulated. Model errors are assessed against observational data spanning a range of variables. This approach is one method of representing and assessing uncertainty in the climate models, and is an alternative approach to using projections from a range of different climate models (Collins et al. 2011).

Currently available climate models developed at different institutions represent the Asian monsoon with variable skill (Turner and Slingo 2009) and present conflicting outcomes; in some cases future strengthening of the summer monsoon circulation are projected (May 2004) and in some cases a weakening (Sabade et al. 2011). For validation, it is therefore important that climate models simulate the present-day rainfall during the summer monsoon period reasonably well in order to produce userrelevant climate projections into the future. However, it should be noted that a model which performs well in a present-day evaluation may not necessarily perform as well under different future forcing scenarios (Knutti 2008).

To gain an understanding of how well the RCM used in this research simulates present-day climate, a range of observational datasets of temperature and rainfall were compared with the model output for the period of 1981-2000. The comparison for the region shows that the simulations provide a good representation of the spatial patterns of temperature and rainfall for 1981-2000. Considering the annual cycles, the simulations tend to overestimate temperatures by around $1{ }^{\circ} \mathrm{C}$ during March to June (Fig. 11.2, upper). In terms of representing the timing and magnitudes of monsoon rainfall, the simulations tend to be reasonably effective, but show a slightly early peak in monsoon rainfall, and an overestimation of 

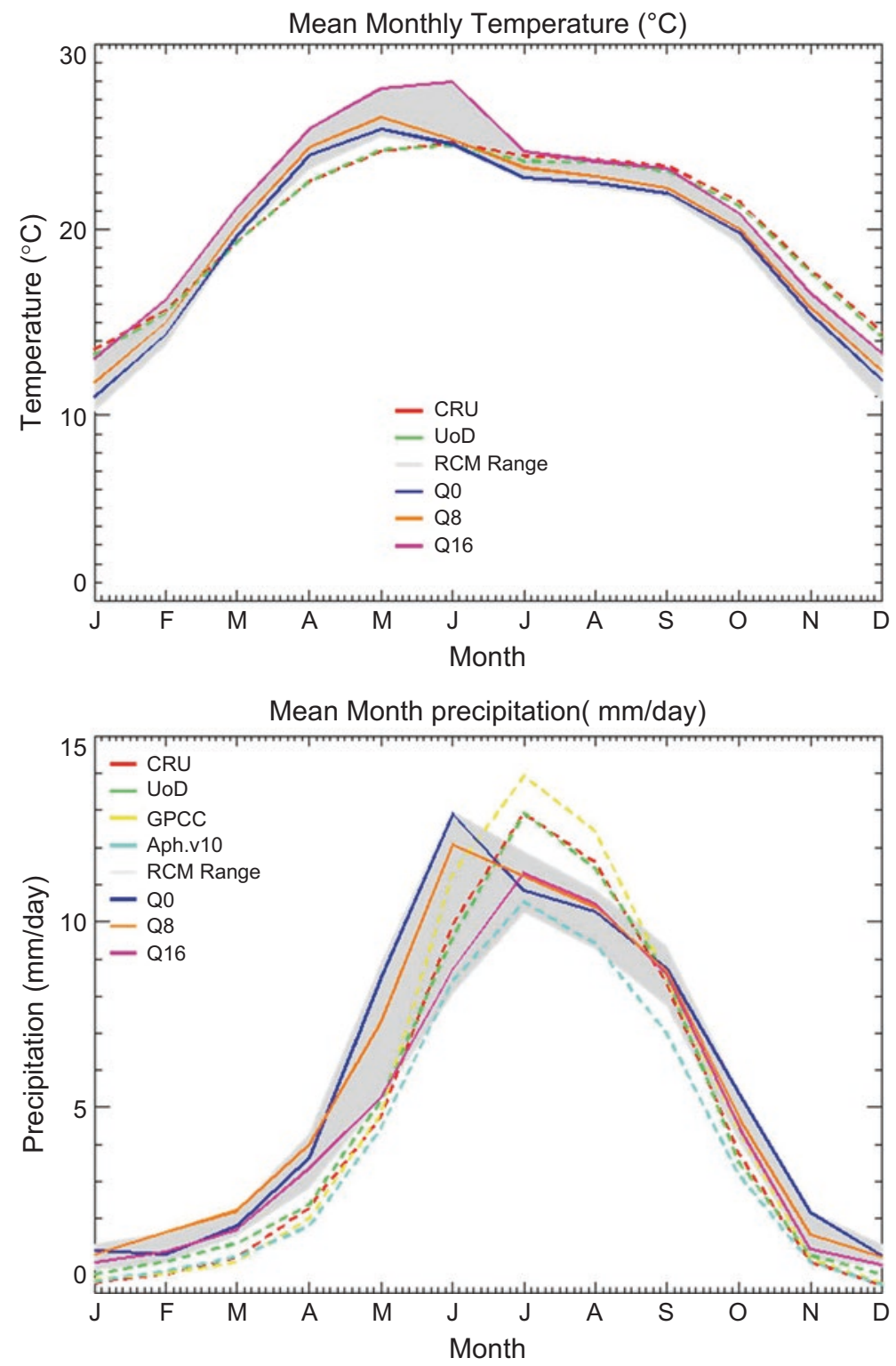

Fig. 11.2 Mean monthly temperature $\left({ }^{\circ} \mathrm{C}\right)$ (upper) and precipitation $(\mathrm{mm} /$ day) (lower) over the GBM sub-region (shown in Fig. 11.1) for the period of 1981-2000 for the RCM 17 member ensemble range (shaded), three selected RCM ensemble members (Q0, Q8 and Q16), and the relevant observational datasets. Dashed lines indicate observations (Caesar et al. 2015-Reproduced by permission of The Royal Society of Chemistry) 
rainfall compared with observations through most of the year, except during the monsoon season itself when simulated rainfall amounts fall within the observational range (Fig. 11.2, lower).

\subsection{Future Climate Change Projections for Bangladesh}

To simulate future climate change, a number of inputs to the model need to be defined. These include the concentrations of greenhouse gasses such as carbon dioxide and methane. A range of future scenarios exist which represent a spectrum from low to high future greenhouse gas emissions. These are determined based upon detailed scenarios which represent a storyline of how the world could develop and includes factors such as potential economic and technological changes (Nakićenović et al. 2000).

The climate model simulations use the Special Report on Emissions Scenarios (SRES) A1B scenario, which was generated for the IPCC Third Assessment Report (2001), but is still used widely in climate change studies (IPCC 2014). The A1B scenario assumes a global future of strong economic growth and an increase in the rate of greenhouse gas emissions over the twenty-first century. The IPCC Fifth Assessment Report (IPCC 2013) uses a new set of scenarios called Representative Concentration Pathways (RCPs) (Moss et al. 2010). RCPs differ from the SRES scenarios in that SRES scenarios used socio-economic storylines as the basis to derive climate change pathways, whereas RCPs start from different levels of radiative forcing at the year 2100, which are then used to derive greenhouse gas concentration pathways for the twenty-first century. Whilst the methodologies are different, which can make comparisons between the scenario sets challenging, it is possible to identify analogues between the two sets of scenarios (Rogelj et al. 2012). SRES A1B is situated between the two high-end RCPs (RCP6.0 and RCP8.5) in terms of the projected global temperature increase by the year 2100 and atmospheric $\mathrm{CO}_{2}$ concentration levels. The projections from the RCM used in this study show a consistent signal of increasing temperatures over the region during the twenty-first century (Fig. 11.3). By the 2060s, the 

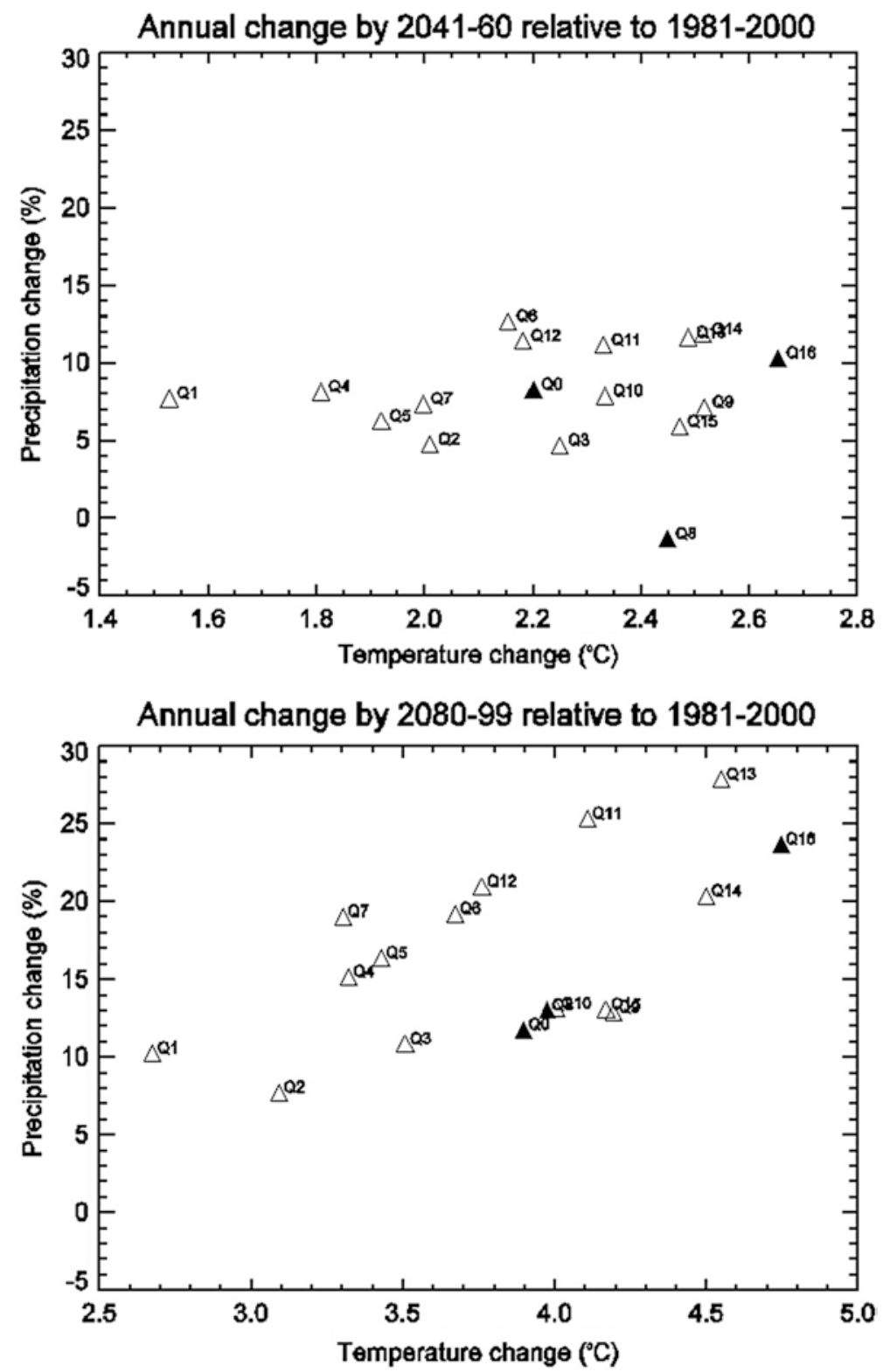

Fig. 11.3 Annual mean temperature and precipitation responses in the 17 regional climate model simulations over the GBM region for 2041-2060 (upper) and 2080-2099 (lower). Filled triangles indicate the three climate projections selected (Caesar et al. 2015-Reproduced by permission of The Royal Society of Chemistry) 
temperature, based upon the $\mathrm{A} 1 \mathrm{~B}$ emissions scenario, is projected to increase by between $1.5^{\circ} \mathrm{C}$ and $2.7^{\circ} \mathrm{C}$, and by the $2090 \mathrm{~s}$ it is in the range of $2.6-4.8^{\circ} \mathrm{C}$.

There is also a consistent signal, using this particular climate model, towards increasing annual rainfall by the end of the twenty-first century (Fig. 11.2). The range of projections for the 2080 s is between +8 per cent and +28 per cent relative to 1981-2000. However, it should be noted that year to year variability is large. By 2050 the range is between -1.4 per cent and around +13 per cent compared to present day. The projections also show a decrease in light to moderate rainfall events, a slight increase in heavy events and a large increase in very heavy events (Caesar et al. 2015). So, despite a decrease in the overall number of days with rainfall, the intensity on the days when rainfall occurs is projected to increase. This could result in flooding and have an impact upon the availability of fresh water during the agricultural calendar.

From the total of 17 RCM simulations, three were selected for application within the other biophysical models (Table 11.1, Figs. 11.4 and 11.5). One was chosen based upon the model variant that represents the 'standard' model parameter configuration (known as Q0). Two additional simulations were chosen for their ability to span a wide range of uncertainty across the full collection of 17 model simulations. The first of these, Q8 indicates warmer but drier conditions compared to the present day in the 2060s, but warmer and wetter by 2090 . The other simulation (Q16) projects the largest temperature increase by both 2050 and 2090, and also large precipitation increases at both 2050 and 2090.

Table 11.1 Annual mean temperature and precipitation changes relative to 1981-2000 in three selected regional climate model projections at the middle and end of the twenty-first century over the GBM region

\begin{tabular}{lccccc}
\hline & \multicolumn{2}{c}{ Temperature $\left({ }^{\circ} \mathrm{C}\right)$} & & \multicolumn{2}{c}{ Precipitation (\%) } \\
\cline { 2 - 3 } \cline { 5 - 6 } Model simulation & $2041-2060$ & $2080-2099$ & & $2041-2060$ & $2080-2099$ \\
\hline Q0 & +2.20 & +3.90 & & +8.26 & +11.75 \\
Q8 & +2.45 & +3.98 & & -1.35 & +13.01 \\
Q16 & +2.65 & +4.75 & & +10.28 & +23.66 \\
\hline
\end{tabular}


(a) Q0

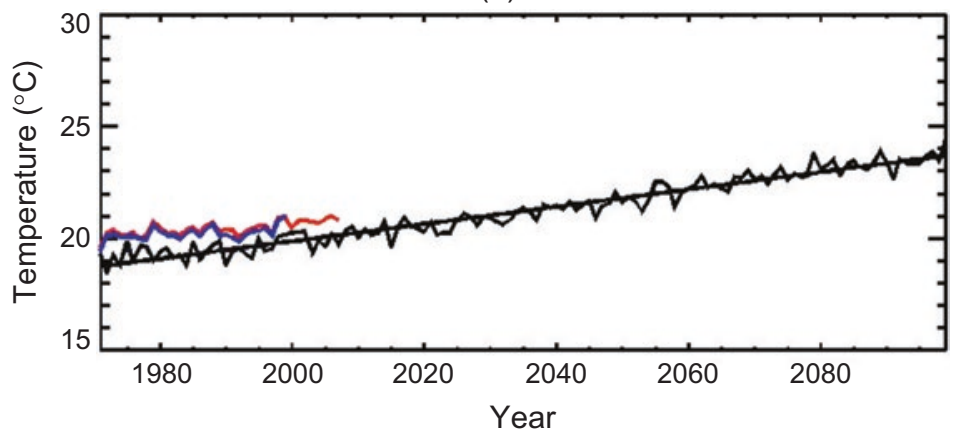

(b) Q8

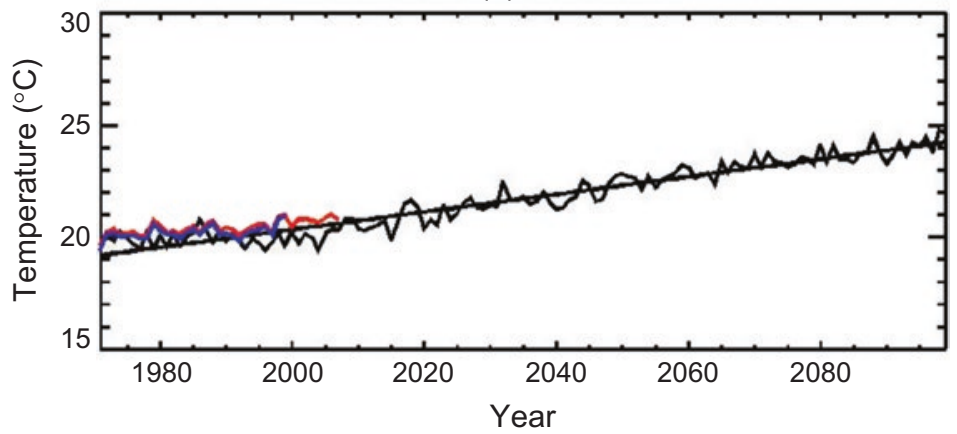

(b) Q16

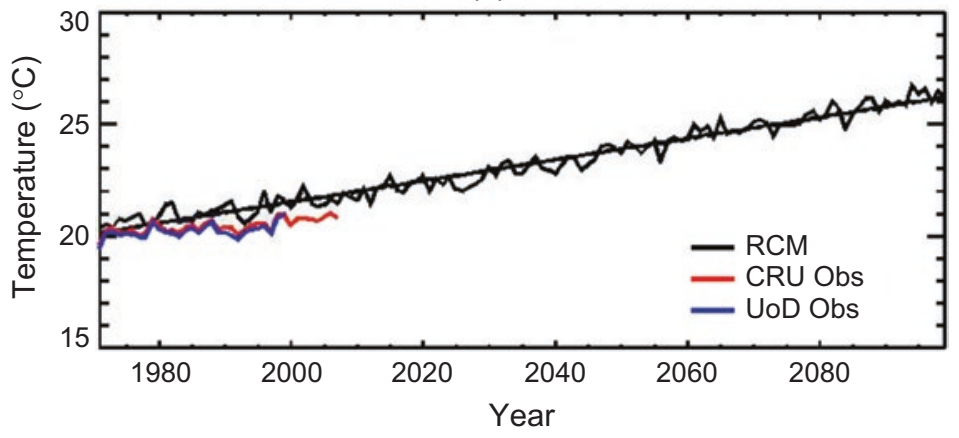

Fig. 11.4 Annual mean time series and trend of air temperature at $1.5 \mathrm{~m}$ for each of the selected climate projections from 1971-2099 inclusive for the GBM region. Coloured lines indicate two observational datasets (Caesar et al. 2015Reproduced by permission of The Royal Society of Chemistry) 
(a) Q0

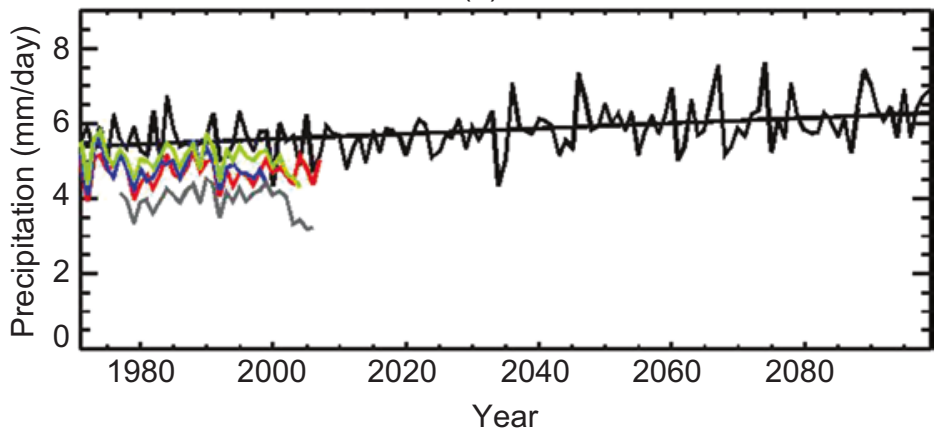

(b) Q8

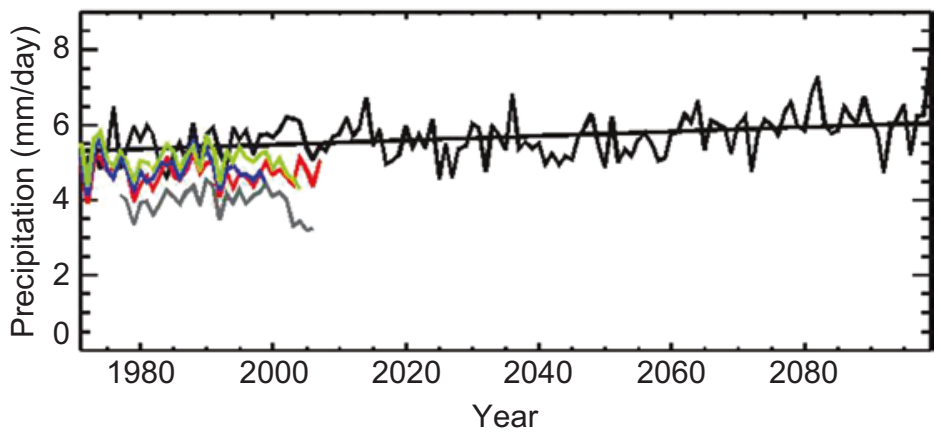

(c) Q16

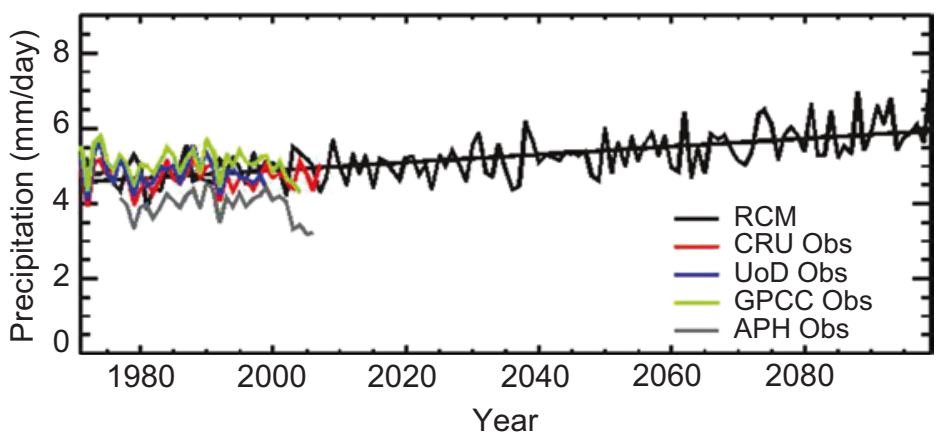

Fig. 11.5 Annual mean time series and trend of precipitation for each of the three selected climate projections from 1971-2099 inclusive for the GBM region. Coloured lines indicate four observational datasets (Caesar et al. 2015Reproduced by permission of The Royal Society of Chemistry) 


\subsection{Conclusions}

A total of 17 high-resolution regional climate model simulations were used to asses future climate change over Bangladesh, with three being selected to drive a range of biophysical impact models. The simulations used the SRES A1B greenhouse gas emissions scenario, which is a mid- to high-range representation of potential future emissions. Three simulations, which represent a range of future temperature and rainfall changes, were selected for use in the more detailed impact sector models.

The projections show an increase in temperature over the region through the twenty-first century, of between around $2.6^{\circ} \mathrm{C}$ and $4.8^{\circ} \mathrm{C}$ by 2100. Rainfall changes are projected to be more variable, but generally show increases ranging from 8 to 28 per cent by the end of the century. Additionally, the frequency of heavy rainfall events is projected to increase in the future, with decreases in the frequency of lighter rainfall. This indicates a shift towards a lower number of wet days, but an increase in intensity on those days when rain falls. This implies an increased risk of flash flooding and a potential change in the freshwater availability across Bangladesh.

As further high-resolution climate projections become available for the Bangladesh region, it will be possible to better assess the differences between different climate models, and also a wider range of greenhouse gas emissions scenarios, and therefore provide improved assessments of the ranges and uncertainties associated with future climate change over Bangladesh.

\section{References}

Agrawala, S., T. Ota, A.U. Ahmed, J. Smith, and M.V. Aalst. 2003. Development and climate change in Bangladesh: Focus on coastal flooding and the Sundarbans. Paris: Organisation for Economic Co-operation and Development. www. oecd.org/env/cc/21055658.pdf. Accessed 28 June 2016.

Caesar, J., T. Janes, A. Lindsay, and B. Bhaskaran. 2015. Temperature and precipitation projections over Bangladesh and the upstream Ganges, Brahmaputra 
and Meghna systems. Environmental Science-Processes and Impacts 17 (6): 1047-1056. https://doi.org/10.1039/c4em00650j.

Collins, M., B.B.B. Booth, G.R. Harris, J.M. Murphy, D.M.H. Sexton, and M.J. Webb. 2006. Towards quantifying uncertainty in transient climate change. Climate Dynamics 27 (2-3): 127-147. https://doi.org/10.1007/ s00382-006-0121-0.

Collins, M., B.B.B. Booth, B. Bhaskaran, G.R. Harris, J.M. Murphy, D.M.H. Sexton, and M.J. Webb. 2011. Climate model errors, feedbacks and forcings: A comparison of perturbed physics and multi-model ensembles. Climate Dynamics 36 (9-10): 1737-1766. https://doi.org/10.1007/ s00382-010-0808-0.

Giorgi, F., C. Jones, and G.R. Asrar. 2009. Addressing climate change needs at the regional level: The CORDEX framework. World Meteorological Organisation Bulletin 58 (3): 175-183.

Immerzeel, W. 2008. Historical trends and future predictions of climate variability in the Brahmaputra basin. International Journal of Climatology 28 (2): 243-254. https://doi.org/10.1002/joc. 1528.

IPCC. 2013. Climate change 2013: The physical science basis. Contribution of working group I to the fifth assessment report of the intergovernmental panel on climate change. Cambridge, UK/New York: Cambridge University Press.

- 2014. Climate change 2014: Impacts, adaptation, and vulnerability. Part A: Global and sectoral aspects. Contribution of working group II to the fifth assessment report of the intergovernmental panel on climate change. Cambridge, UK/New York: Cambridge University Press.

Islam, M.N., and H. Uyeda. 2005. Comparison of TRMM 3B42 products with surface rainfall over Bangladesh. In Geoscience and remote sensing symposium (IGARSS) 2005, 25-29 Seoul.

Islam, M.N., M. Rafiuddin, A.U. Ahmed, and R.K. Kolli. 2008. Calibration of PRECIS in employing future scenarios in Bangladesh. International Journal of Climatology 28 (5): 617-628. https://doi.org/10.1002/joc.1559.

Karim, M.F., and N. Mimura. 2008. Impacts of climate change and sea-level rise on cyclonic storm surge floods in Bangladesh. Global Environmental Change-Human and Policy Dimensions 18 (3): 490-500. https://doi. org/10.1016/j.gloenvcha.2008.05.002.

Knutti, R. 2008. Should we believe model predictions of future climate change? Philosophical Transactions of the Royal Society A: Mathematical, Physical and Engineering Sciences 366 (1885): 4647. https://doi.org/10.1098/ rsta.2008.0169, Licence https://doi.org/10.1098/rsta.2008.0169. 
Kumar, P., A. Wiltshire, C. Mathison, S. Asharaf, B. Ahrens, P. Lucas-Picher, J.H. Christensen, A. Gobiet, F. Saeed, S. Hagemann, and D. Jacob. 2013. Downscaled climate change projections with uncertainty assessment over India using a high resolution multi-model approach. Science of the Total Environment 468: S18-S30. https://doi.org/10.1016/j.scitotenv.2013.01.051.

Mathison, C., A. Wiltshire, A.P. Dimri, P. Falloon, D. Jacob, P. Kumar, E. Moors, J. Ridley, C. Siderius, M. Stoffel, and T. Yasunari. 2013. Regional projections of North Indian climate for adaptation studies. Science of the Total Environment 468: S4-S17. https://doi.org/10.1016/j.scitotenv.2012.04.066.

May, W. 2004. Potential future changes in the Indian summer monsoon due to greenhouse warming: Analysis of mechanisms in a global time-slice experiment. Climate Dynamics 22 (4): 389-414. https://doi.org/10.1007/ s00382-003-0389-2.

Moss, R.H., J.A. Edmonds, K.A. Hibbard, M.R. Manning, S.K. Rose, D.P. van Vuuren, T.R. Carter, S. Emori, M. Kainuma, T. Kram, G.A. Meehl, J.F.B. Mitchell, N. Nakicenovic, K. Riahi, S.J. Smith, R.J. Stouffer, A.M. Thomson, J.P. Weyant, and T.J. Wilbanks. 2010. The next generation of scenarios for climate change research and assessment. Nature 463 (7282): 747-756. https://doi.org/10.1038/nature08823.

Murphy, J.M., D.M.H. Sexton, D.N. Barnett, G.S. Jones, M.J. Webb, M. Collins, and D.A. Stainforth. 2004. Quantification of modelling uncertainties in a large ensemble of climate change simulations. Nature 430 (7001): 768-772. https://doi.org/10.1038/nature02771.

Nakićenović, N., J. Alcamo, G. Davis, B. Devries, J. Fenhann, S. Gaffin, K. Gregory, A. Gruebler, T.Y. Jung, T. Kram, E. Lebre Larovere, L. Michaelis, S. Mori, T. Morita, W. Pepper, H. Pitcher, L. Price, K. Riahi, A. Roehrl, H.-H. Rogner, A. Sankovski, M. Schlesinger, P. Shukla, S. Smith, R. Swart, S. Vanrooijen, N. Victor, and Z. Dadi. 2000. Special report on emissions scenarios, a special report of working group III of the intergovernmental panel on climate change. Cambridge, UK: Cambridge University Press.

Rogelj, J., M. Meinshausen, and R. Knutti. 2012. Global warming under old and new scenarios using IPCC climate sensitivity range estimates. Nature Climate Change 2 (4): 248-253. https://doi.org/10.1038/nclimate1385.

Sabade, S.S., A. Kulkarni, and R.H. Kripalani. 2011. Projected changes in South Asian summer monsoon by multi-model global warming experiments. Theoretical and Applied Climatology 103 (3): 543-565. https://doi.org/ 10.1007/s00704-010-0296-5. 
Shahid, S. 2010a. Rainfall variability and the trends of wet and dry periods in Bangladesh. International Journal of Climatology 30 (15): 2299-2313. https:// doi.org/10.1002/joc.2053.

2010b. Recent trends in the climate of Bangladesh. Climate Research 42 (3): 185-193.

Turner, A.G., and J.M. Slingo. 2009. Uncertainties in future projections of extreme precipitation in the Indian monsoon region. Atmospheric Science Letters 10 (3): 152-158. https://doi.org/10.1002/asl.223.

Open Access This chapter is licensed under the terms of the Creative Commons Attribution 4.0 International License (http://creativecommons.org/licenses/ by/4.0/), which permits use, sharing, adaptation, distribution and reproduction in any medium or format, as long as you give appropriate credit to the original author(s) and the source, provide a link to the Creative Commons license and indicate if changes were made.

The images or other third party material in this chapter are included in the chapter's Creative Commons license, unless indicated otherwise in a credit line to the material. If material is not included in the chapter's Creative Commons license and your intended use is not permitted by statutory regulation or exceeds the permitted use, you will need to obtain permission directly from the copyright holder.

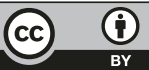

